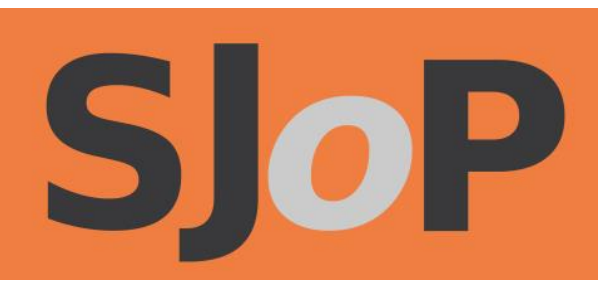

\title{
Interview: Trio HLK
}

\section{BENJAMIN REDMAN}

The Scottish Journal of Performance

Volume 5, Issue 2; September 2018

ISSN: 2054-1953 (Print) / ISSN: 2054-1961 (Online)

Publication details: http://www.scottishjournalofperformance.org

To cite this article: Redman, B., 2018. Interview: Trio HLK. Scottish Journal of Performance, 5(2): pp.85-101.

To link to this article: http://doi.org/10.14439/sjop.2018.0502.05

(c) (1)

This work is licensed under a Creative Commons Attribution 4.0 International License. See

http://creativecommons.org/licenses/by/4.0/ for details. 
INTERVIEW:

\title{
Trio HLK
}

\author{
BENJAMIN REDMAN
}

DOI: 10.14439/sjop.2018.0502.05

Publication date: 30 September 2018

Trio HLK is an ensemble that draws on elements of jazz and contemporary classical music, and pushes the boundaries of both genres. They recently collaborated with Dame Evelyn Glennie (arguably the world's foremost solo classical percussionist) and Dr Steve Lehman (contemporary jazz saxophonist and Guggenheim Fellow) on their debut album recording, Standard time. The trio launched Standard time at a concert featuring Evelyn Glennie at the Queen's Hall, Edinburgh, on 13 May 2018. This article is based on extracts from an interview conducted several days after the concert with Richard Harrold and Richard Kass, in which they discussed a wide range of topics, including their rehearsal and compositional processes, collaborations, performing, and development as an ensemble.

\section{Introduction}

Formed in Edinburgh in 2015, Trio HLK consists of pianist and composer Richard Harrold, drummer / percussionist Richard Kass, and eight-string guitarist Ant Law. The ensemble was described by BBC Jazz on 3 as 'One of the most exciting young ensembles to have emerged in the last year' (Ubuntu Music, 2018). Many of the compositions on their debut recording Standard time are based on 'standard' jazz tunes, which are deconstructed and then reconstructed using elements 'such as fragments of melody or harmony, which then become the raw material for intricate new 
pieces, resulting in familiar threads leading the listener into distant territory' (Trio HLK, 2018).

Evelyn Glennie commented, 'Collaborating with Trio HLK has been a wonderful journey of exploration, a challenge that I have thoroughly enjoyed. It has allowed me to venture out of my comfort zone, explore new rhythms and marvel at the Trio's compositional prowess' (Ubuntu Music, 2018).

The band are performing an ongoing series of concerts throughout 2018 and 2019, details of which can be found here: http://www.triohlk.com/itinerary.php

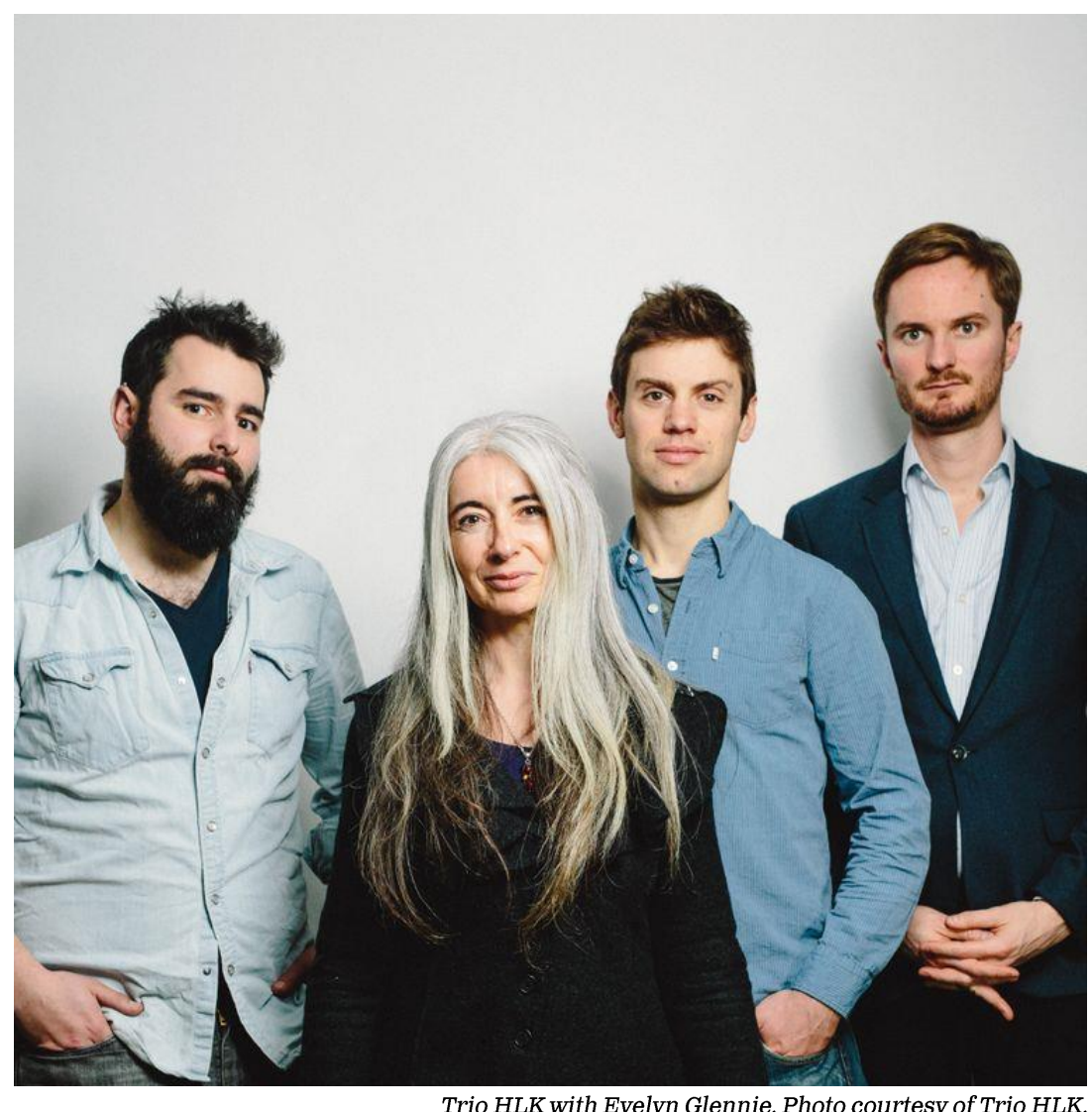

Trio HLK with Evelyn Glennie. Photo courtesy of Trio HLK. 


\section{Compositional process}

Benjamin Redman: Could you talk me through some of your compositional processes? I know from the Standard time sleeve notes and from what you talked about at the concert, a lot of the tunes are based on deconstructed standards.

Richard Harrold: I often choose a standard that has really strong melodic or motivic content, things that have a really strong identity, and then just take those bits and then work with them as much as possible. So, it's just borrowing chunks of material that hopefully people recognise, or at least think they might know-they're supposed to be quite on the edge of recognition.

\section{Smalls}

RH: The first tune on the album is 'Smalls'. The structure consists of two main rhythmic forms. The first one you hear as an extended introduction-that section uses the descending whole tone motif from the start of 'Blue in Green' [Miles Davis tune from the album Kind of blue].

Richard Kass: It's a four-bar form and the time signatures are 13/16, 11/16, 13/16, 9/16.

RH: And that's it, it's just a four-bar pattern, but that's cycled as a background rhythmic pattern and we improvise freely around that. Usually, one of us is asserting that form at any one time. And then the second rhythmic structure is a bit more complicated; it's just an eight-bar form, but it's switching between thirteens, elevens, nines-basically, irregular time signatures. It's not terribly brutal to learn, but again, it's long enough and unpredictable enough that probably nobody in the audience quite has it learned by the end of the piece! 
RK: It also flies by-it is crotchet equals 120 [beats per minute], but those notes are all dotted, so when improvising on the form, if you forget where you are, a couple of bars can go by before you manage to make eye contact to see what's going on.

$\mathrm{RH}$ : One of the main things that we like to do in all of the tunes is play around with your perception of where the beat is, so when it moves by quite quickly it can sound like it's in four, but a wonky four. So that thirteen sounds like a $4 / 4$ groove that's a bit out of time, but we're all 'out of time' in unison. It's a fun effect-strict counting that gives the impression of sloppiness.

https://www.youtube.com/watch?v=dQMsp2By9z4

Video: Trio HLK featuring Evelyn Glennie 'Extra Sensory Perception part i'.

Extra Sensory Perception parts i and ii

RH: The next tracks are 'Extra Sensory Perception parts i and ii'. We did discuss keeping them as one track, but then we thought it was quite a nice compositional thing to have it chopped into these two quite different sections; so part $i$ is the vibes and piano intro, and part ii is the band piece, but it's based on the same material.

BR: So, it's based on the Wayne Shorter tune 'ESP'; which elements did you extract from that?

$\mathrm{RH}$ : For the vibes and piano intro, the ostinato that you hear is the original tune with the melodic pattern condensed, with all the rhythm taken out of it. It just becomes an ostinato and it kind of sounds like a swing rhythm, but again, slightly out of time. It's a bar of $9 / 8$, but hopefully it 
sounds like a wonky three-three-two, and then on top of that you get lots of overlaid melodic fragments.

RK: That was one of the first tunes that we played when we started playing together. In some ways, I still find that the hardest because I think I'd have to go back to it to play it in the same depth that I play some of the other tunes. I'm going to revisit it, I'm just waiting on my crotales arriving, and there's going to be a couple of sections where I'm going to play some pitched stuff on it in unison. But it's funny how that happens-the older material is more frustrating to play through, because at the time I maybe didn't have the same facility or the ideas, it was like just trying to get through the tune! But once you get used to the rhythmic material, all these things you've worked on, you start to see how they can work. I look at it now and I can see all the possibilities.

\section{http://www.triohlk.com/downloads.php}



First page: 'Extra Sensory Perception' (copyright Richard Harrold). 
pains parts $\mathrm{i}$ and ii

RK: 'painS' is based on the Chick Corea composition 'Spain', which has got quite a lot of ideas in it; this one is maybe the most full of material. So really, the whole composition is about six sections long, and each one of them works on a different part of the original tune.Hopefullythey're fairly recognisable, they're a bit less obscure than the material used in some of the other pieces.

$\mathrm{RH}$ : Part $\mathrm{i}$ of this composition is an improvisation by Steve Lehman; I sent him a two-bar motif, and this movement is just an improvisation on that motif.

Twilt

$\mathrm{RH}$ : The next track is 'Twilt', based on 'The way you look tonight', but it's 'The way I look tonight'. A lot of the titles are just in-jokes. 'Twilt' is based on perceived beats, there are quite a lot of expanding and contracting false beats. Something I do for quite a lot of the tunes is rather than thinking of a chord sequence, I will use a particular intervallic idea. This tune is based on perfect fifths and major seconds, different combinations of them being placed next to each other in different configurations. I'm just moving these symmetrical shapes around each other, and the harmony emerges from that. Quite a lot of the tunes have that sort of harmonic approach.

\section{Dux}

RK: Rich had originally come up with a piece based on some motifs that would be heard in Latin or Afro-Cuban music and I thought it would be a good way to explore doing some stuff with the clave. I guess quite a few times, an idea comes up in the tune, and if it works, I then try and use the tune as a way to really explore that idea, to go into depth with it. So, as well as playing it within the trio, I've added it to my 
vocabulary. A lot of the drum parts, and a couple of bits of the composition towards the end, get based on the 3:2 rhumba clave, and the very start of the tune is like the rhumba clave in four different sub-divisions, layered so you hear them at four different tempos, but they're all metrically related.

RH: 'Dux' is all in 4/4; actually, it's the only tune on the album that is. But then, the clave is kind of pinning the whole thing together with all these other motifs shifting around each other in different rhythmic patterns.

RK: On some of the tracks on the album, the drums serve to highlight the interplay of the guitar and the piano. In the 'head' of Dux, the piano plays montuno vamp patterns and the guitar plays the tumbao bass pattern, and the drums pick out both parts. While they shift around each other, the clave continues in $4 / 4$, pinning the two together. Several of the tracks on the album use the drum set as a sort of glue for the shifting polyrhythms of the other instruments.

$\mathrm{RH}$ : It helps pin these things together. Without the drums working this way, some of the parts of complicated counterpoint might seem a bit too unrelated to be cohesive, but the kit helps to bind the thing together. However, this orchestrational technique also means that it's very obvious when one of us messes up!

\section{Chewy}

RK: That's the shortest tune on the album, and has one of my favourite solo forms in it, because there are quite a lot of time signature changes. There's a sort of distorted symmetry at the start of the form, and a real asymmetry at the end of the form. At the start of the form, there are always three bars of $4 / 4$, followed by an irregular time signature. 
The first group of these is three bars of $4 / 4$ and then a bar of $3 / 4$; the next group is three bars of $4 / 4$ and a bar of $9 / 16$; the next is three bars of 4 then 11/16; and finally, three bars of 4 and a $7 / 16$. So, with all the $4 / 4$ stuff, it's quite an easy form to play on, but punctuated by these interesting moments of irregularity. It sounds quite mathy, but it's really not. After a while you start to realise lots of opportunities for overlaying different rhythmic patterns; for example, dotted notes can go across whole swathes of sections, which helps to create tension and release, and the numbers happen to work out so that dotted patterns resolve at the starts of sections. For me, the composition has a really interesting solo form-there are a lot of different things that can be explored.

The coda is another example of a section in which the drums pick out the two parts of counterpoint as a kind of orchestrational glue. Behind this, the drums also play a Bossa Nova style bass pattern which keeps getting chopped up. In fact, the whole piece has that sort of samba rhythm driving it, but often with extra bits of beats chopped in or out.

RH: It's a very contrapuntal piece. I really love J.S. Bach's two part inventions, the way that the lines are always perfectly interweaving; separate, but totally interdependent. And the coda to this piece is a sort of counterpoint exercise in that vein, a counterpoint exercise from hell!

\section{Stabvest}

RH: It was originally called 'Stabfest', but there's already a version of 'Stabfest' out there, so we renamed the album version. It was called 'Stabfest' because it's so full of stabs! Rhythmically, it's based on groups of five, seven and three; a lot of it is in 4/4, playing with different groupings over a $4 / 4$ pulse. Because we're not stating the actual pulse, it gives the 
effect of speeding up and slowing down. If you're not hearing the true pulse then you get this shifting effect.

RK: And in both the solo sections there's an interesting thing-both of the solos in the rhythm section can be played in four, or can be played within the groupings. So, with quite a lot of the tunes where that's the case, we can go into different gears or try and play in the sevens for a while, and then the whole rhythm section can be speeding up and slowing down. On the other hand, it can be really open, so you can start it very sparse, and then suddenly it morphs into something else.

$\mathrm{RH}$ : But we're really just counting the same thing underneath it. This is another one that is all based on the same harmonic idea-it's just second inversion chords. Before I figured out their order, I just sat and played through different configurations and second inversions placed next to each other, decided which ones were good, and then just sat and arranged them. They're all just major triads, and the harmony for the solos just emerges from those patterns.

\section{The Jig}

RH: It's from J.S. Bach's 'First Cello Suite in G Major', but you can't really hear it, it's been so distorted. The compositional process was quite non-linear for that piece, it's been through a lot of incarnations. Originally, two of the sections that are still in the piece had the melody superimposed and reharmonised, and it was reworked and revised a lot; and then, essentially, most of the melody has been airlifted out. I quite like the idea of that though, it's almost like it was a sort of scaffolding to build this piece, and then the scaffolding has come down, but the piece is there because of that scaffolding. 


\section{Rehearsing and performing}

BR: How long does it take from writing a chart to having it rehearsed and ready to perform?

RH: They're always evolving, but I suppose it's definitely months, rather than days. Each of the pieces generally has a fairly complicated improvising form as well, so that's often one of the biggest obstacles. Learning the dots is fairly tricky too, but that's just a matter of bedding them in; whereas, being able to freely improvise over a new rhythmic framework, it has to be really deeply ingrained so that you can actually hear phrases and rhythmic patterns against it, so that's the stuff that really takes lots of playing in.

RK: Normally, we can quite easily play through the parameters of the form, but having enough headroom to be playful and musical with it, and be responsive, and to be really thinking and able to concentrate on the tempo for example; you just have to get the stuff to the point where you've got the headroom to play it and not be counting. The goal is to play it as well as you'd just be playing a $4 / 4$ blues.

$\mathrm{RH}$ : It's still a work in progress with most of them to be honest. Some of them are getting quite comfortable now, but we're definitely still improving them.

RK: One of the reasons they can take a long time is that we play through them and things need to change, parts change. Almost all of the charts have got things that are scribbled out.

$\mathrm{RH}$ : It's about making them feel the correct length, and after playing something quite a bit, it might seem fine at first, but then we might feel it's just not sitting right in this bit, and we need to take that out. It's a constant workshopping process, 
which is one of the great things about working in a band where you rehearse so regularly-it's not like one of those gigs where you show up and hand the parts out.

BR: I noticed you were wearing in-ear monitors on stage.

RK: We're playing in a lot of different large spaces on this tour with Evelyn, and in spacious venues, on-stage monitors make a big difference to the overall sound. Not having monitors on stage makes it a lot easier to amplify an acoustic sound and make it sound good: not too loud at the front, and not too quiet at the back. It also means the sound is really consistent for us from gig to gig. I think in the past when we've used wedges [floor monitors], because the music is quite loud at points, the tendency is for the volume to creep up. It creates a stage volume that really affects the sound in the venue. So, my favourite way to play now is when we play almost acoustically, just a guitar amp and nothing else!

RH: We've started doing more and more trio gigs without any amplification, which is quite nice. As long as we've got a decent piano and a smaller drum kit, it works quite well.

RK: And it's been great learning to play with the same intensity, but quietly. It's involved, for me anyway, some technique changes, but it's been amazing for being able to play across the dynamic range and separate all those things out. When I'm practising, I might think 'OK, I can play that, but will I be able to play it in the Leggate Theatre, when Rich $\mathrm{H}$ is on an un-amplified grand piano and the room has got a three-second decay?' It just changes your attitude to practising everything you do. Now that we're frequently dealing with so many different spaces and levels of amplification, you have a reason to practise whatever it is 
you're practising at all dynamic ranges, and to try and master the same articulation.

BR: How much do you rely on visual cues on stage?

RK: Because of the nature of the forms being quite complicated, things are normally cued a lot. So, if you miss a cue it can be difficult, like if somebody goes on and somebody else doesn't, then it can cause a bit of mayhem. So, on stage we always have to have a really good line of sight. We make decisions about putting things in places where sometimes it's not great for the audience. We try and avoid that, but you know, sometimes Rich $\mathrm{H}$ might have his back to the audience, which probably isn't ideal. But if he was further over and at a better angle, then I wouldn't be able to see him, which might cause problems!

RH: Yes, I definitely look over at Kass a lot, probably more than I even realise; and actually, there are probably visual cues that I'm responding to that I'm not even really fully aware of. Line of sight is crucial for playing this music.

\section{Instrumentation and genre}

BR: I noticed you have some custom bells and cymbals on the kit, and you mentioned about getting crotales, are you going to be using more tuned percussion?

RK: That's the plan, yes. I guess at this point, I'm really lucky to have an endorsement with Sabian [cymbal manufacturer]; they basically opened the door to me being able to experiment with quite a lot of different things, so the idea is to integrate the crotales. I'm really interested in four-way coordination [using all four limbs], which I think is still very early on in its development. I think what could be done with the kit could be so far beyond where it is now. I really like 
the idea of maybe using the feet to be playing kicks and snares, and trying to do some harmonic stuff with one or two hands. Certainly, there are sections of music where I could just play some tuned percussion, but I like the idea of maybe having a bit of both in there somehow. That's certainly something I'd like to investigate more, but I could lose a couple of years to that, you can go quite deep into that kind of thing!

RH: This music sounds a lot like jazz, but, I think that's mainly due to the instrumentation. I really like the idea of the drum kit expanding into something more like percussion, because for me, this music is at least as connected to twentieth-century classical music as it is to jazz.

BR: What was the motivation for Ant getting his eight-string guitar?

RH: He's learned the eight-string just for this project! Since we don't have a bass player, it's great having two instruments that can still inhabit that register. So, we can share that role, or chose to leave space down there.

BR: We've already touched on genres, would you prefer not to be pigeon-holed?

RH: I think it's very hard to talk about musical genre at all these days. All these different genres are constantly feeding into each other and influencing each other. I think there are a lot people from the non-jazz world who might be interested in this music, and particularly those people who are interested in contemporary classical music. We're keen to reach as wide an audience as possible. 
RK: It's a difficult one to contemplate as it's all so interrelated. Everything is so cross-pollinated now. One of the things that the three of us in the trio share is an interest in great composers, great performers, improvisation, rhythm, and harmony. And there is so much amazing, intelligent music happening in so many different areas right now. One example would be electronic music. There is a whole generation of players, especially drummers, who are reverse engineering electronic music techniques and taking their influence from that. Jojo Mayer has developed drumming techniques that no one else has really used before, in order to replicate that music live. So, electronic drum programming and sampled music are influencing the performer, and even the performance and the technique to some extent. I find it hard to separate any of it, it's all just music, and interesting musicians trying to produce good music.

BR: Can you tell me a bit more about what interests you about JoJo Mayer, is it more his techniques or his musical concepts?

RK: Well both-he's broken both the techniques and the concepts down in different areas through his DVDs and through his TED talks. I was fortunate to do a little bit of studying with him a few years ago where I learned a lot about technique, which I'm still trying to work on, but he's obviously developed ways of playing the cymbal and the snare drum very quickly with fast bursts of motion. People saw Buddy Rich do some of that stuff, but he's really worked that vocabulary, with arguably a greater dynamic range, into a lot of music which requires that technique to be able to play such fast cymbal work that was originally played much slower, and then sped up in samplers. And even the design of the instrument-he's designed these dry cymbals which sound very sampled. And then there's his theory of reverse engineering, where he's taking the vocabulary of 
programmers, like the phrase 'this sentence will repeat', and it's chopped up to 'this, this, sen, sen, tence, tence, will, will, repeat', and then build up a rhythmic pattern off one chunk of vocabulary. You can compare that idea of working with motivic fragments and developing them to some of the things you hear in contemporary classical music, and definitely in improvisation-the way people develop chunks and fragments and move them around and chop them up.

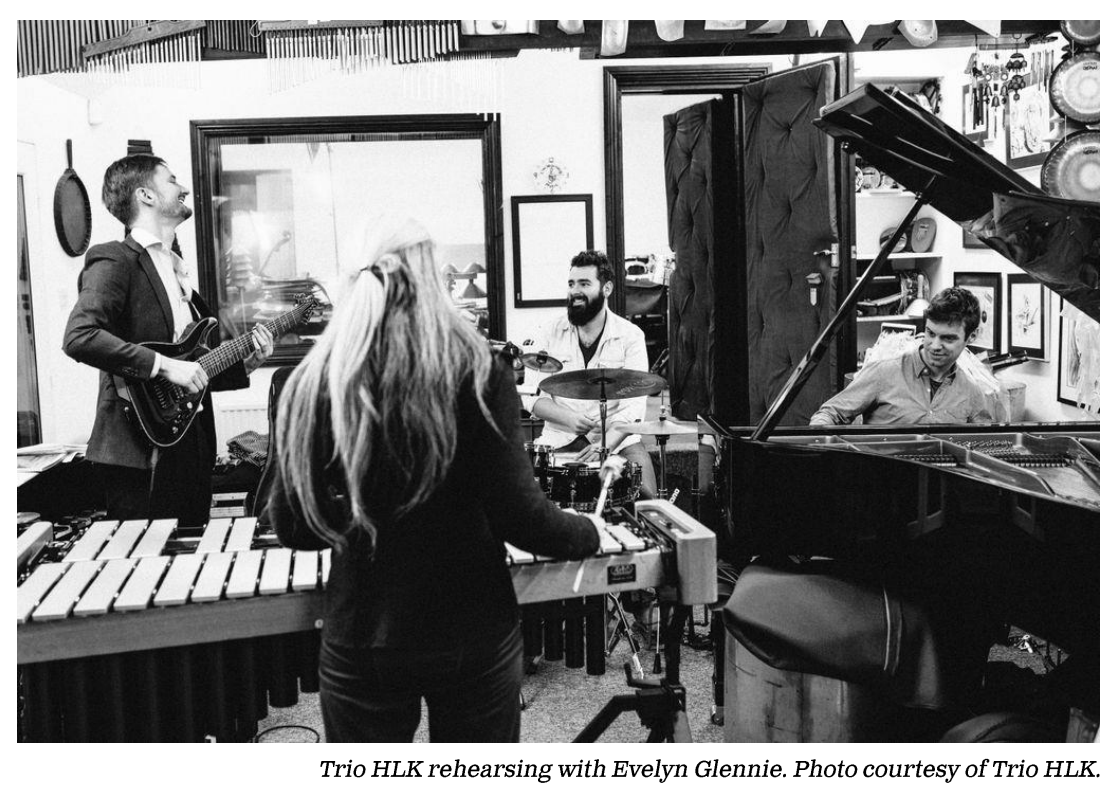

\section{Collaborations and development}

BR: How did your collaborations with Evelyn Glennie and Steve Lehman come about?

RH: We just sent Evelyn some of the music, asked her if she'd be up for it, and she was, and the same with Steve. They were both very, very easy to work with, and incredibly lovely, good-natured, and inspiringly good!

RK: They both commented on how difficult the music wasyou sometimes forget when you inhabit it all the time. Even for those two, who are so incredibly high up musically, some 
of those things might have been unfamiliar, or they might have had to spend some time working on it.

We went to see Steve play at the Bimhuis in Amsterdam, and he did this great microtonal sax intro, and so hearing that vocab led us to ask him to play an intro to one of our pieces. We opened for Chris Potter's trio at Ronnie Scott's back in March for three consecutive nights, and every night we would watch them play, which was so inspiring. The next day we would go and practise and we'd talk about how great their improv was-the different ways they really opened things up-and we'd try to apply some of that to our improv.

We don't just try and make the audience happy, but we do take into account how the audience responds to the music or the flow of the set, and that's had an impact on how we approach the improv sometimes. Thinking back to our first gigs, everything was really full-on all the time, but we've worked on trying to make the set feel balanced in terms of space and intensity. It comes back to having the mental headroom to control what we're doing now that we know the music a lot better than we did at first, when we were probably more concerned with just trying to play the notes correctly. Now, I really make an effort to try and make the music as engaging and as expressively played as possible. That's not saying that if people don't like it we change it-we don't do that at all-but we do try and think about the overall listening experience, even just where we put things in the set, so that people are able to relax and breathe between the more intense passages of music. And again, it comes back to our own experience when we watch music together. We talk about that-how everything flowed and whether we were able to concentrate for the full length of the concert.

RH: It's a funny one that isn't it, having to be aware of the whole gig. Because when I'm working on an individual tune, I'm just thinking about how that tune works in its best 
possible way, but then if you end up with ten very intense tunes, it's not going to work for an audience-well, maybe one or two people. So, it's then a matter of seeing what can be tweaked in order to make the whole thing sit as one performance; it's not easy.

\section{Acknowledgements}

With grateful thanks to Richard Harrold and Richard Kass for generously sharing their time, and for permission to reproduce images and links from the Trio HLK website.

\section{References}

Trio HLK, 2018. [Online]. Available at: 〈http://www.triohlk.com $〉$ [Accessed 16 September 2018].

Ubuntu Music, 2018. [Online]. Available at: 〈http://www.weareubuntumusic.com/trio-hlk-spotify/〉 [Accessed 16 September 2018].

\section{About the author}

BENJAMIN REDMAN is a musician, a teacher, and a $\mathrm{PhD}$ researcher at the Royal Conservatoire of Scotland. His research interests include the use of videoconferencing in instrumental music teaching. He has presented at international conferences, most recently at the Performance Studies Network conference at the Norwegian Academy of Music, Oslo, July 2018. 